\title{
Measurement of an Upper Limit of Fission Energy Release in HOLOG using a Germanium Gamma-Ray Detector
}

\author{
Tzu-Fang Wang
}

Allen V. Friensehner

Ronald W. Lougheed

January 1998






\section{DISCLAIMER}

This document was prepared as an account of work sponsored by an agency of the United States Government. Neither the United States Government nor the University of California nor any of their employees, makes any warranty, express or implied, or assumes any legal liability or responsibility for the accuracy, completeness, or usefulness of any information, apparatus, product, or process disclosed, or represents that its use would not infringe privately owned rights. Reference herein to any specific commercial product, process, or service by trade name, trademark, manufacturer, or otherwise, does not necessarily constitute or imply its endorsement, recommendation, or favoring by the United States Government or the University of California. The views and opinions of authors expressed herein do not necessarily state or reflect those of the United States Government or the University of California, and shall not be used for advertising or product endorsement purposes.

This report has been reproduced directly from the best available copy.

Available to DOE and DOE contractors from the Office of Scientific and Technical Information P.O. Box 62, Oak Ridge, TN 37831

Prices available from (423) 576-8401

Available to the public from the National Technical Information Service

U.S. Department of Commerce 5285 Port Royal Rd., Springfield, VA 22161 
Measurement of an upper limit of fission energy release in HOLOG

using a germanium gamma-ray detector*

Tzu-Fang Wang, Allen V. Friensehner, and Ronald W. Lougheed

Isotope Sciences Division

Lawrence Livermore National Laboratory

Livermore, CA 94550

\begin{abstract}
Summary
An upper limit of less than $4 \mathrm{mg}$ TNT equivalent fission energy release from the HOLOG experiment was determined using a germanium $\gamma$-ray detector to measure the ratio of selected fissionproduct and plutonium $\gamma$ rays. Only three hours of $\gamma$-ray data collected immediately after the zero-time were analyzed to calculate the above limit. We found no peaks corresponding to the ${ }^{97} \mathrm{Zr}-{ }^{97} \mathrm{Nb}$ fission product pair at the gamma-ray energies of $\mathrm{E}_{\gamma}=743$ $\mathrm{keV}$ and $\mathrm{E}_{\gamma}=658 \mathrm{keV}$, respectively. No information on the plutonium isotopic ratios is revealed because $\gamma$-ray peaks in the energy region below $100 \mathrm{keV}$ are not observed due to the high absorption in the containment barrier. The measurement is relatively easy to perform and is not subject to false-positive results because specific fission product and plutonium $\gamma$ ray energies need to be detected.
\end{abstract}


Measurement of the spectrum of gamma-rays emitted by plutonium and its fission products, if any, from a subcritical experiment (e.g., HOLOG) can be used to inexpensively and reliably obtain a limit of the plutonium fission efficiency (i.e., the fraction of plutonium that fissioned). In this study, we apply such a measurement through the HOLOG containment barrier. The actual quantity we measured is the ratio of fission product $\gamma$-rays to plutonium $\gamma$-rays. Knowing the time of the experiment, start and stop time of the measurement, and documented fission product yields ${ }^{1}$ (e.g., the fraction of fissions that result in an atom of ${ }^{97} \mathrm{Zr}$ ), one can convert this ratio to plutonium fission efficiency. However, one needs to make an assumption that the fission is uniformly mixed throughout the plutonium. To the extent that the fission to plutonium ratio varies, the measurement will be less accurate because the detector only "sees" the $\gamma$-rays from any fission products and plutonium that are closest to it. It is possible to take data at several positions outside the containment barrier to check for uniformity although for HOLOG a single detector and single counting position were used. The total fission energy release can then be estimated from the measured fission efficiency knowing the mass of plutonium used in the experiments.

One can select from a large number of possible fission products for this measurement. The best choices have a high fission product yield, half-lives comparable to a realistic measurement time soon after the zero time, and have high-energy high-abundance $\gamma$-rays per decay. Some choices which meet these criteria are the ${ }^{97} \mathrm{Zr}\left(\mathrm{t}_{1 / 2}=16.8 \mathrm{~h}, \mathrm{E}_{\gamma}=743 \mathrm{keV}\right)$ and ${ }^{97} \mathrm{Nb}\left(\mathrm{t}_{1 / 2}=1.2 \mathrm{~h}, \mathrm{E}_{\gamma}=658 \mathrm{keV}\right)$ pair 
and the ${ }^{140} \mathrm{Ba}\left(\mathrm{t}_{1 / 2}=12.75 \mathrm{~d}, \mathrm{E}_{\gamma}=1510 \mathrm{keV}\right)$ and ${ }^{140} \mathrm{La}\left(\mathrm{t}_{1 / 2}=1.68 \mathrm{~d}\right.$, $E_{\gamma}=1597 \mathrm{keV}$ ) pair. The mass-97 and mass-140 chains each have high fission branches ( 5\%). The mass-97 chain half-lives are short enough to permit a high fraction of the decays to be observed but also long enough to allow measurements if data accumulation could not start until reentry of the tunnel was allowed. For these reasons, and to limit additional costs from a more complicated data analysis, we chose to simply use a measurement of the ${ }^{97} \mathrm{Nb}-{ }^{97} \mathrm{Zr} \gamma$ rays to determine a limit for the plutonium fission efficiency. Gamma rays from these nuclides are normalized to one of the two strongest ${ }^{239} \mathrm{Pu}$ intrinsic $\gamma$-rays in the $400-\mathrm{keV}$ energy region, either the $375-\mathrm{keV}$ or $414-k e V{ }^{239} \mathrm{Pu} \gamma$-rays.

A high purity germanium (HPGe) detector with a $\gamma$-ray detection efficiency of $70 \%$ (compared to a 3 " $\times 3$ " sodium iodide (Nal) detector) was used to measure the $\gamma$-rays up to $3 \mathrm{MeV}$ from both the ${ }^{239} \mathrm{Pu}$ and the fission products. ( $\mathrm{Nal}$ and other kinds of $\gamma$-ray detectors do not provide sufficient energy resolution.) This detector, surrounded by a $1 / 4$ " thick $\mathrm{Pb}$ collimator, was placed facing the containment barrier that consists of 1 " thick steel and 12 " thick concrete. In order to increase the ${ }^{239} \mathrm{Pu}$ detection efficiency after the experiment, we placed the detector as close to ground level as possible assuming that the $\mathrm{Pu}$ concentration in the chamber would be highest at the chamber floor, as shown in Figure 1. Signals from the detector were amplified via standard electronics and recorded in a PC-based data acquisition system. (Figure 2) We also programmed the data acquisition software to perform hour-by- 
hour histogram dumping so that data can be segmented into one-hour intervals.

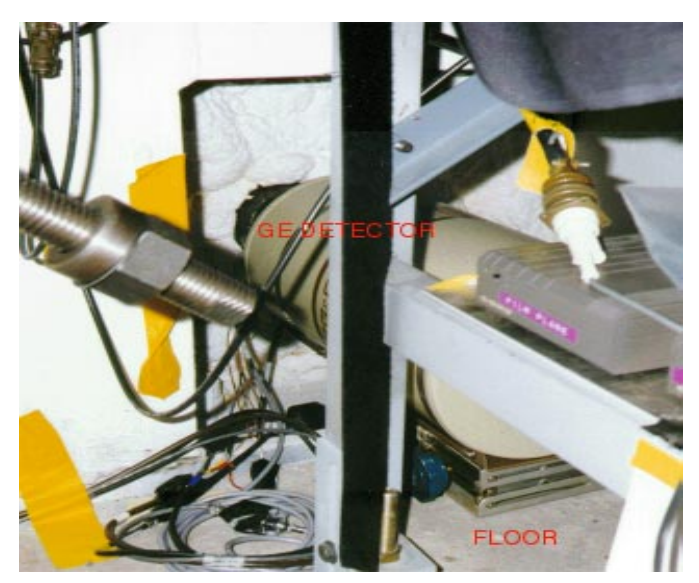

Figure 1. The Ge detector was placed as close to the ground level as possible.

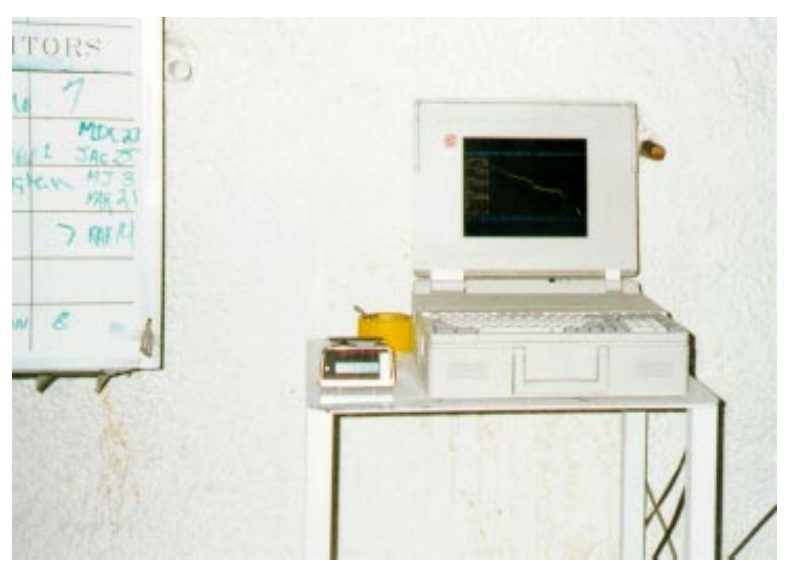

Figure 2. A PC laptop based data acquisition system was placed next to the sign-in board outside the zero room.

We collected thirty-six hours of $\gamma$-ray background data before the plutonium was moved into the zero room, fifteen hours of $\gamma$-ray data after the plutonium was moved into the zero room, and sixtyseven hours of $\gamma$-ray data after the zero time. A 15-hour $\gamma$-ray spectrum (Figure 3) taken before any $\mathrm{Pu}$ was placed in the zero room 
was normalized to 3 hours for comparison with the first three hours of data collected after zero time (Figure 4). Figure 5 shows an expanded view of the ${ }^{97} \mathrm{Zr}$ and ${ }^{97} \mathrm{Nb} \gamma$-ray energy peak positions from the same three-hour spectrum shown in Figure 4. In all of the collected spectra, the $100-\mathrm{keV}$ region is completely attenuated due to the containment barrier. Therefore, no information on the isotopic composition of $\mathrm{Pu}$ that was used in the experiment can be deduced. The strong 375- and 414- keV $\gamma$-ray peaks in Figure 4 demonstrate that the $\mathrm{Pu}$ indeed scattered all over the zero room after the blast. 


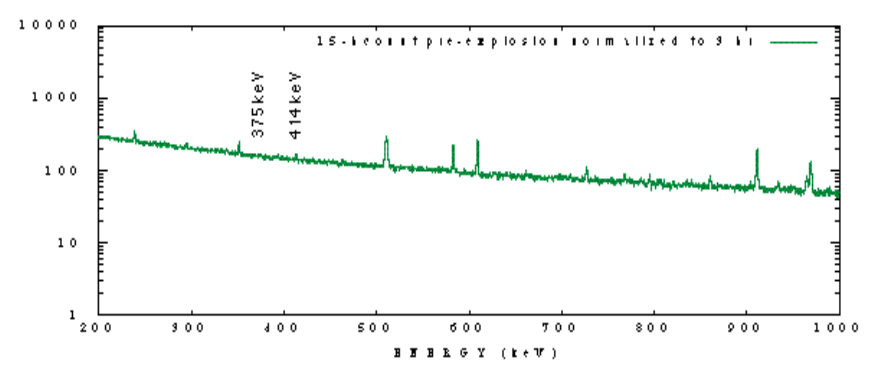

Figure 3. Background $\gamma$-ray spectrum (collected for 15 hours and normalized to 3 hours for comparison with the 3-hour postexperiment spectrum in Figure 4) before the plutonium was moved into the zero room.



Figure 4. Three-hour $\gamma$-ray spectrum collected immediately after the zero time.

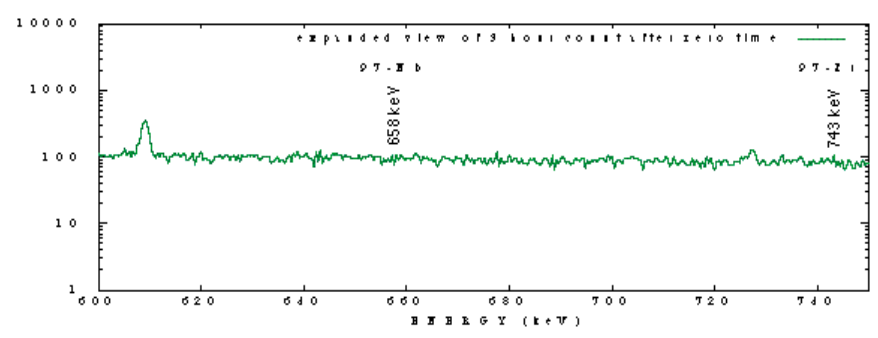

Figure 5. Expanded view of the same three-hour $\gamma$-ray spectrum shown in Figure 4 showing the expected $\gamma$-ray energy peak positions of ${ }^{97} \mathrm{Zr}$ and ${ }^{97} \mathrm{Nb}$.

Spectra were analyzed using an graphic PC version of GAMANL, ${ }^{2}$ one of the long integrated spectra collected after the zero time was analyzed using $\mathrm{MGAHI}^{3}$ to obtain the combined transmission and the 
detector efficiency. Prior to the experiment, we have also performed Monte Carlo calculations of the combined transmission and detector efficiency. The simulation results are in good agreement with results from the MGAHI fitting within $10 \%$.

Results from GAMANL show that an integrated $1627+-8 \%$ counts under the $375-\mathrm{keV}{ }^{239} \mathrm{Pu}$ peak in the three-hour spectrum that were collected after the zero time. We have also found no evidence for a peak at either the 658- and $743-\mathrm{keV}{ }^{97} \mathrm{Zr}$ and ${ }^{97} \mathrm{Nb}$ peak energies in the same spectrum (expanded region is shown in Figure 5). To estimate upper limits of counts at 658- and 743- keV peaks with backgrounds, we used standard statistical methods ${ }^{4}$ to estimate counts in Gaussian peaks with fixed full-width-halfmaximum energy resolution and found upper $3 \sigma$ limits ( $99.74 \%$ confidence level) of 66 counts and 66 counts for the 658- and 743$\mathrm{keV}$ peaks, respectively. The combined transmission and detector efficiency obtained from the MGAHI fitting is $4.2 \times 10^{-7}$ for $\gamma$-ray energy of $375 \mathrm{keV}$ and $1.5 \times 10^{-6}$ for gamma-ray energy of $743 \mathrm{keV}$.

One milligram of TNT equivalent fission energy release will produce $1.4 \times 10^{11}$ fissions for $\mathrm{n}+{ }^{239} \mathrm{Pu}$. By folding this number with the combined transmission and detector efficiency, the branching of the $\mathrm{n}+{ }^{239} \mathrm{Pu}$ to ${ }^{97} \mathrm{Zr}-{ }^{97} \mathrm{Nb}$ pair, the half-lives of the pair to the total collecting time, and finally, normalized with respect to the ratio of ${ }^{239} \mathrm{Pu}$ viewed by the germanium detector to the total ${ }^{239} \mathrm{Pu}$ used in the experiment. We obtain an upper limit of $4 \mathrm{mg}$ of TNT equivalent fission energy release from the three-hour spectrum collected immediately after the zero time. We predicted ${ }^{5}$ similar sensitivity prior to the measurement. Our current calculated sensitivity could 
be improved by at least a factor of 10 if we can 1) employ shorter data dumping time intervals or collect the data in list mode and 2) analyze the spectra in detail for multiple fission products, especially those with shorter half-lives when the counting takes place through zero time. Then it is possible to select fission products with half-lives of minutes which would completely decay during a short counting time $\left(20 \%\right.$ of the ${ }^{97} \mathrm{Nb}$ decayed during the 3 hour counting interval used to calculate the fission efficiency) as well as correspondingly reducing the background. However, because the experimental objectives were met, a more complicated analysis that would result in higher expenses was not performed.

In summary, we have proved that a single shielded HPGe detector outside the containment barrier of a subcritical experiment can be used to measure the plutonium fission efficiency and total fission yield from HOLOG. By carefully choosing the detection geometry, the data acquisition sequence, and the fission product, we are able to achieve a detection sensitivity of better than $4 \mathrm{mg}$ of TNT equivalent fission energy release. To apply this measurement technique to future subcritical experiments, we note that if the containment barriers are substantially thicker (e.g., REBOUND), a reentrant tube or other means would be needed to prevent increased $\gamma$ ray absorption. The measurement is relatively easy to perform and is not subject to false-positive results because specific fission product and plutonium $\gamma$ ray energies are measured.

1 T.R. England and B.F. Rider, "Evaluation and Compilation of Fission Products Yields", ENDF-349, LA-XXXX-MS, 1993 
${ }^{2}$ R. Gunnink, J.B. Niday, UCRL-51060, 1997. Graphics and PC port was made by T.F. Wang.

${ }^{3} \mathrm{MGAHI}$ is currently under development by T.F. Wang. This is a high energy only ( > $200 \mathrm{keV}$ ) version of MGA. The MGA was developed by R. Gunnink, and Wayne D. Ruhter, UCRL-LR-103220, 1990.

${ }^{4}$ W.T. Eadie, D. Drijard, F.E. James, M. Roos, B. Sadout "Statistical methods in experimental Physics" pp. 272. North-Holland-Publishing, 1971.

5 "Subcritical Experiments," Jason Report, JSR-97-300, MTTRE Corporation, Jan. 21, 1997. 


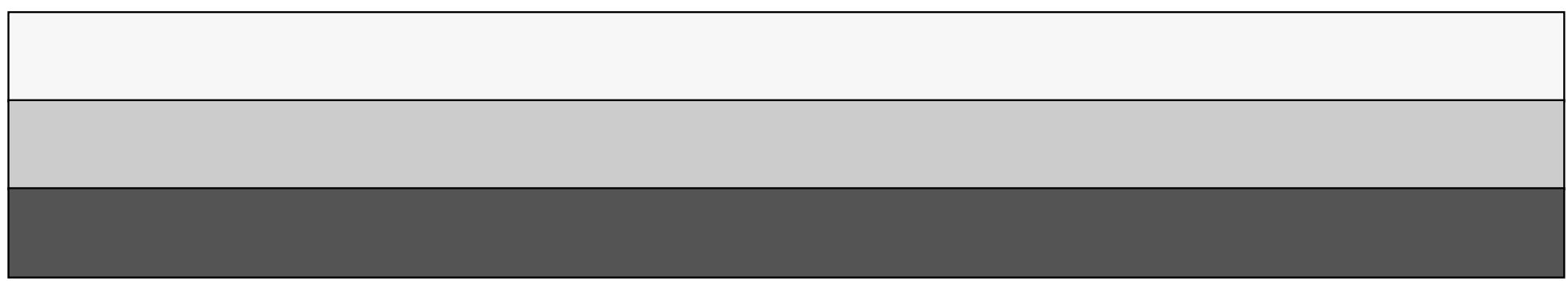

